\title{
Social Security Income and Household Savings: A New Model and Evidence
}

\author{
Simin Mozayeni \\ State University of New York at New Paltz
}

Our motivation for this research is to contribute to the debate about the effect of expected social insurance income during retirement on private household saving, generated by Feldstein (1974) and several responses to it. We consider an alternative model to the Life Cycle Model and empirically test it for G7 and for 27 OECD countries. Our dependent variable is Household Saving Rates, whereas the dependent variables are the Gross Replacement Rates (GRR) and Interest Rate. We do not consider the effect of income simply because, for some countries -saving is a percentage of income. Neither, we consider the effect of income inequality on household savings, due to missing data for many countries. We test the null hypothesis, whether expected social insurance benefits in retirement displace household private savings. We reject the null. The main contribution of this research to the literature is that our new model removes the uncertainty of estimation of expected cash income in retirement. Despite plausible results we obtain, a more extensive GRR data would have been desirable.

Keywords: Social Insurance, Households' Private Savings and Social Insurance, Gross Replacement Rates, OECD Households' Saving Behavior, A New model, G7 Households' Saving Behavior, A New Model for Estimation of the Effect of Social Security Income on Household Savings

\section{INTRODUCTION AND LITERATURE REVIEW}

Martin Feldstein (1974), using the life Cycle Model and Time Series, proposed that social security benefits displace household private savings by about 50\% in US. That work led to several other studies that questioned Feldstein's finding. The literature is 50-50 divided on that. Among them, the Social Security Bulletin publication by Louis Esposito (1978) considered four empirical studies of the effect of the US social security program on private saving and concluded that none of those studies support the hypothesis that the social security system decreases households' private saving. Because Esposito drew upon the research of Robert Barro, Michael Darby, Martin Feldstein, and Alicia Munnell, they were invited to comment on the conclusions the author drew from their work. Their comments are reported in "Social Security and Private Saving: Another Look," Social Security Bulletin (May 1979, Vol. 42 (5), pp. 33-40). In sum, Barro agrees with Esposito, Darby does not, and Feldstein suggests the need for "new data and new approach," stating that "Without new data or a new approach, the analysis of the time-series data would be stalled at this point." (P. 37). And Alicia Munnell agrees with Esposito. Overall, together, these scholars raise doubt about the conjecture that expected social insurance income during retirement offsets households' private savings. 
Leimmer and Lesony (1982) also refute Feldstein's (et al, 1974) proposition. Overall, the literature is split 50-50 on acceptance of the proposition and raises serious questions about the assumptions of the Life Cycle Model, and the uncertainty of estimation of the stream of benefits, saving motivations among cultures and age groups, among others. We consider several key pieces of literature.

Gale (1998), uses a Life Cycle model for saving that accounts for shortcomings of previous studies. Gale uses data from the 1983 Survey of Consumer Finances (SCF), which contains interviews with a cross-section of 3,824 U.S. households, and a supplemental survey of 438 high-income households. Gale excludes farmers from his survey based on the fact that they have a different saving pattern from other households, ala Avery (1986) and Hubbard (1986). Gale concludes that the model embodies complete offset between pensions and other wealth. Gale also notes that consumption in each period depends on the present value of total consumption, but not allocation of compensation between wages and pension. In conclusion, Gale refutes the proposition that expected social insurance income offsets households' private savings.

Lesnoy and Leimer (1985) use a historical aggregate time series with sample data for US. They consider the debate since 1974 and observe that $50 \%$ of the literature reject the offset of household savings: Alicia Munnell (1974), Robert Barro (1978), Michael Darby (1979) contradicting Feldstein et al. 1974. They also consider the less technical guide to early debate including Selig Lesnoy and John Hambor (1975); Louis Esposito (1978); Dean Leimer (1980; Selig Lesnoy (1980) and the second paper by Barro, Darby and Munnell (1983). Lesnoy and Leimer concluded that in the context of the historical evidence they reviewed, found no support for Feldstein's hypothesis. (p. 14-15).

Furthermore, Lesnoy and Leimer, consider the theoretical factors affecting saving for retirement. They also note that the relationship between aggregate savings and individual savings is not simple in growing economies (aggregate saving is positive in growing economies). They comment that substitution of social security wealth, measured by its present value of future expected benefits, for ordinary wealth, raises a question about their asset substitution effect. They also suggest ambiguity of the effect of social security savings on private household saving, adding: "Many social scientists question the LIFE Cycle model." (P. 16) They express concerns about the assumptions of the Life Cycle Model, including the rationality of individuals for making rational, complex decisions.

Rocher and Stierle (2015), note that saving motives vary across cultures, and economies. That raises a host of issues in the Life Cycle Model and beyond, including the potential effect of interest rate on household savings. They suggest that higher interest rates may tend to increase household saving, on the one hand, and on the other hand, people may attempt to smooth their consumption and postpone their current consumption. Consequently, they may tend to save more and slow their consumption. Hence, the effect of interest rate on household savings is ambiguous. According to Rocher and Stierle, the sign of the coefficient for the interest rate could be either positive or negative.

Based on this body of literature and more to follow, we offer an alternative model to the Life Cycle Model, as we delineate below.

Attanasio and Brugiavini (2003) show age could also affect workers' decision about savings. They consider the effect of the 1992 Italian pension reform and measure the elasticity of household saving to changes in future pension entitlements. As they correctly note, "this elasticity is obviously related to the degree of substitutability between pension and bequeathable wealth." They find evidence that as the result of reduction in pension wealth, saving rates increase in their data. They find that worker age 35-45 are most likely to substitute private savings for pensions. We do not account for age in our model.

Rocher and Stierle (2015), suggest that "income distribution" can also affect savings. Explaining that countries with unequal income distributions (commonly measured by the Gini Coefficient) are likely to have higher saving rates. Households with higher disposable income tend to save more of their income than households at the lower end of the income distribution. At the aggregate level, this would suggest that income inequality tends to increase the household saving rate. In our model, we do not include the Gini Coefficient, due to missing data for many countries.

The key literature clearly questions the generalization that expected social security income displaces households' private savings and raise serious issues with the Life Cycle Model. With such background 
and the availability of Gross Replacement Rate data for measurement of expected social security income, we developed a new model for assessment of their effect on households' savings, and empirically validated it for the $\mathrm{G} 7$ and a group of 27 OECD countries. We tested the null hypothesis, whether expected social insurance benefits in retirement displace household private savings. We rejected the null hypothesis. Our results show no evidence that social security income displaces household private savings in the group of countries we considered, for the ten years (2004-2014) we considered. The rest of the paper is organized as follows.

In the section immediately following this section, we describe our Model, Data, and the rationale for using a Unit Root Test for determining if we needed to treat the data as nonstationary. We also elaborate on our model and estimations, which include other tests for determining our methodology. In that section, we also describe the results of our statistical analyses for G7 and the 27 OECD countries. We then report our Conclusion and Summary in the last section of the paper. In the Data Appendix (A-J), we report our counties' data, the results for all verification tests, and the regression results for G7 and 27 OECD group of countries.

\section{THIS STUDY}

\section{The Model}

As noted above, the Life Cycle model has several shortcomings on several fronts, including, uncertainty about future streams of retirement income.

We propose an alternative model for estimation of the effect of social insurance income on household saving that depends on individuals' expectation of their actual Gross Replacement Rates (GRR). Our model includes the rate of interest as a key variable. We do not include income in our model because some countries' measure of "household savings" is a percentage of income. Neither, we include the Gini Coefficient because the data were missing for many countries, nor do we include Age (suggested in the literature). Before conducting our regressions, we run a battery of tests to evaluate the nature of our data and validity of the model we use. Accordingly, we selected our model. Our estimation equation is presented below, in equation (1).

$H S_{i}=\beta_{i t}+\beta_{1} G R R_{i t}+\beta_{2} L T I R_{i t}+\varepsilon_{i t}$

\section{The Data}

The data for this study is from the OECD database, recorded in Appendix A. Gross Replacement Rates (GRR) are obtained from OECD's biennial report Pension at a Glance. Our dataset encompasses 27 OECD countries as a group for which data were complete for 2004-2014, and G7. Our 27 countries are: (1) Australia, (2) Austria, (3) Belgium, (4) Canada, (5) Czech Republic, (6) Denmark, (7) Finland, (8) France, (9) Germany, (10) Greece, (11) Hungary, (12) Ireland, (13) Italy, (14) Japan, (15) Korea, (16) Mexico, (17) Netherlands, (18) New Zealand, (19) Norway, (20) Poland, (21) Portugal, (22) Slovak, Republic, (23) Spain, (24) Sweden, (25) Switzerland, (26) United Kingdom, and (27) the United States. Accordingly, our data is a panel set.

As illustrated in Table A in the Appendix, household saving rates differ substantially among the OECD countries, and year to year in the period under consideration. In Table 1 (bellow) we report the Basic Statistics for the variables in our model. Household Saving Rate has a maximum value of $+20.09 \%$ for Switzerland and the minimum value of -17.28 for Greece, both in 2014 (years are given in Appendix A). As recorded in Appendix A, the GRR also varies substantially among the OECD countries, with a maximum of 95.7 for Greece (2006-2010), and as low as 29\% for Ireland (2010). 
TABLE 1

BASIC STATISTICS FOR VARIABLES

\begin{tabular}{|l|c|c|c|}
\hline Basic Statistic & Household Saving Rate & Gross Replacement Rate & Long Term Interest Rate \\
\hline Minimum & -17.28 & 25.48 & 0.519 \\
\hline Median & 4.06 & 52.55 & 4.04 \\
\hline Mean & 4.63 & 54.37 & 4.11 \\
\hline Maximum & 20.09 & 95.70 & 22.50 \\
\hline
\end{tabular}

\section{Preliminary Tests for Verification of Data}

Before proceeding to our estimations, we conducted several tests to verify the nature of our data in order to develop our methodology. We first conducted a Unit-Root test to determine if our time series were stationary or not. Nonstationary data will cause inaccuracies in estimations. We elaborate on our procedure or the Unit Root Test below. The other preliminary tests are integrated into the discussion of the Model and Estimations, as they pertain to the selection of our methodology. We present our tests for multicollinearity and heteroscedasticity in sections designated for each.

\section{Unit-Root Test}

We used the Augmented Dickey Fuller (ADF) test which is set up as such for the variable $y$ in equation (2):

$\Delta y_{t}=\psi y_{t-1}+\varepsilon_{t}$

Our null hypothesis is that $\psi=0$, which indicates a unit root and that the variable is not stationary in our time series. The alternative is that $\psi<0$, indicating a stationary variable. Equation (3) is our test statistic:

$D F_{\tau}=\frac{\widehat{\psi}}{\operatorname{se}(\widehat{\psi})}$

Appendix B details the results of the ADF test. From the results, we see that all three variables (HS, GRR and LTIR) are stationary. Hence no treatment became necessary for using them in our model.

\section{The Model and Estimations}

In this section, we discuss our model and the preliminary tests we sued to validate it, followed by our report for its empirical verifications for both the G7 and 27 OECD groups.

Clearly, pension recipients are better able to optimize their savings during their working years, if they have information about their income replacement rate during retirement. Absence of an accurate measure of expected future social security income obviously weakens workers' estimation of their need for saving for retirement while they work. Such uncertainty plagues the Life Cycle Model.

With publication of the Gross Replacement Rate for 27 OECD member countries, we were able to develop a new model and empirically test it. Hypothetically, GRR information, improves household's foresight and enables them to plan for their retirement, assuming saving motivation is primarily precautionary for "old age." Thus, we abstract from other possible household motivations for saving and assume households' saving decisions are determined by information about their GRR for future income (with expectation of indexing for inflation).

We used a general estimation equation model for evaluating the effect of expected social security income on households' saving, given in equation (1).

Our dependent variable is the private Household Savings (HS), defined by OECD as the difference between household consumption expenditure from household disposable income, plus the change in the net equity of households in pension fund. Our independent variables are Gross Replacement Rate (GRR), 
defined as gross pension entitlement divided by gross-retirement earnings, Long-Term Interest Rate (LTIR), for which OECD uses government bonds that mature in ten years.

In equation (1), $i$ indexes the G7 or the 27 OECD countries, and $t$ the years, whereas $\beta_{1}$ and $\beta_{2}$ indicate the partial effects of Gross Replacement Rate and Long-Term Interest Rate, respectively, on Household Savings. The estimation equation also includes the intercept $\beta_{i t}$ and residuals $\varepsilon_{i t}$.

Since our data consisted of panels, we evaluated three models commonly used for a panel data to determine the appropriate version for our data. With that objective, we considered the Pooled-OLS, Fixed-Effect and the Random-Effect Models. The Pooled-OLS assumes no specific effect between the panels, while the Fixed-Effect Model assumes such differences, and we allowed dummy variables for each country. The Random-Effect Model is a special case of the Fixed-Effect Model, which has random intercepts and partial pooling. Appendix $\mathrm{C}$ details the results of the three models we considered for the 27 OECD group.

From the Pooled-OLS Model, we observe that GRR has insignificant effect on household savings. From the Fixed-Effect Model, we observe that GRR has a small positive coefficient of 0.08 . This means that as GRR increases by one percent, household savings would increase by 0.08 percent. Our RandomEffect Model shows a positive coefficient of 0.06 for GRR. This is less than its effect found in the FixedEffect Model.

Comparing the Pooled-OLS and Fixed-Effect Models, we saw that the $R^{2}$ for the Pooled-OLS was very low compared to the Fixed-Effect Model's, suggesting that the Fixed-Effect fits he better our data better.

Furthermore, we consider the Akaike Information Criterion (AIC) for those two models. The AIC for the Pooled-OLS is 973.57, while for the Fixed-Effect Model is 770.08. We report the results in Appendix D. A lower AIC indicates a stronger model. Therefore, we concluded that the Fixed-Effect Model fits our data better than the Pooled-OLS Model.

To compare the Fixed-Effect Model with the Random-Effect Model, we used the Hausman Test (Appendix E). The Hausman Test verifies the consistency of the Random-Effect Model when compared with the Fixed-Effect Model. The null hypothesis is that the random effect coefficients are consistent and will be more efficient than in the Fixed-Effect Model. The alternative will be that the Random-Effect coefficients are inconsistent. The test statistic for this test has a $\chi^{2}$ distribution. With a P-value less than 0.05, we rejected the null hypothesis of the Hausman test and concluded that the random-effect coefficients were inconsistent. Hence, we determined that the fixed-effect model was the appropriate model for our empirical tests.

While the fixed-effect accounts for differences between the countries, we did not know if time influenced our estimation results or not. Our next test determined if it was necessary to include a measure for the time-effect into our model. We used an F-test to verify that. The null hypothesis for the F-test was "time." If time did not have a significant effect on our results, the alternative would have a significant effect. The result of this test is reported in Appendix F. With P-value greater than 0.05, we did not reject the null. This implied that "time" had no significant effect on household savings (HS) in our data.

With the above analyses, we concluded that the Fixed-Effect Model was the best fit for our panel data among the three commonly used models.

With three statistical diagnostic tests and robust results, we verified the validity of our model and estimations. We described the Unit-Root Test above; and report our test results for multicollinearity and heteroscedasticity below.

\section{Multicollinearity}

Since our model was multivariate, we made sure that none of our variables were collinearly related. Thus, we used the Variance Inflation Factor (VIF) test for collinearity. We report the result in Appendix $\mathrm{G}$ for the generalized Variance Inflation Factor for our independent variables. It is conventional standard that a VIF of less than 12 indicates absence of multicollinearity. From our results, we concluded that multicollinearity is not present in our data. 


\section{Heteroscedasticity}

To test for heteroscedasticity, we used the Breusch-Pagan (BP) test. The BP test has the null hypothesis that a linear model is homoscedastic and an alternative hypothesis that it is heteroskedastic. The test statistic has $\chi^{2}$ distribution. Appendix H details the BP test results. With P-value less than 0.05, we rejected the null. Thus, we accepted presence of heteroscedasticity in our Fixed-Effects Model.

To remedy the heteroscedasticity, we used heteroscedasticity-consistent standard errors. With this method, we constructed new coefficients for our Fixed-Effect Model. These new coefficients are detailed in Appendix I. With these new coefficients, we observed that GRR no longer had a significant coefficient.

First, we considered the G7 countries' panel data and conducted our regression with a fixed-effect. We report the results below.

\section{The Effect of Social Insurance Income on Household Saving: The Case of G7 Group}

We applied the fixed-effect model to examine the effect of the expected social security income, measured by GRR on the household's saving (HS) rates in G7 partition of the OECD data. The subgroup G7 are more heterogeneous in income, as wealthy and developed nations, with comprehensive social pension programs.

The results of the regression are detailed in Appendix $\mathrm{J}$, where we show $\mathrm{R}^{2}$ value of 0.82 , with the coefficient of GRR being +0.11 (at 95\% level of confidence). Our results show a negative sign for the LTIR - the long-term interest rate. The negative coefficient for interest rate suggests that household savings and LTIR move in the opposite direction. On the surface, this appears implausible and unexpected. Yet, ala Rocher and Stierle (2015), the effect of the interest rate on savings is ambiguous. According to them, higher interest rates may tend to increase households' saving on the one hand, and on the other hand, if they attempt to smooth their consumption by postponing current consumption, they may tend to save more and slow their consumption. Hence, the effect of interest rate on Household Savings could be unexpected, as in our regression (s).

Also, we observe that in a regular fixed-effect regression, the GRR does not have a significant effect on HS, but when accounting for heteroscedasticity, the heteroscedasticity-consistent coefficients results have a significant positive value for GRR at +0.11 . Accordingly, an increase of one percent in GRR would increase the household saving rate (HS) by 0.11 percent. With confidence, we confirm that expected social insurance income does not replace the households' private saving in our sample. In fact, they are complements rather than being substitutes.

\section{The Effect of Social Insurance Income on Household Saving: The Case of 27 OECD Group}

Our model is the same as the one we used for G7. In Appendix C, we report our regression results for the Pooled-Panel data for the 27 OECD group. We show that $\mathrm{R}^{2}$ is 0.84 and the coefficient for GRR is + 0.9 (with 95\% significance), indicating that expected Social Security income is a complement to household savings, not a substitute. Again. we find a negative sign for the coefficient of the LTIR, as in the case of the G7 countries, where we referenced Rocher and Stierle (2015), for a discussion of ambiguity of the effect of interest rate on household savings.

\section{SUMMARY AND CONCLUSION}

With availability of Gross Replacement Rates (GRR) data, we have proposed a new model that removes the uncertainties of the Life Cycle model. We have empirically tested our model, examining the effect of GRR on household savings for the G7 and a group of 27 OECD countries. We have used a panel data for 2004-2014 (dictated by data availability). We have selected our model based on the results of a number of preliminary tests, including a Unit-Root test, AIC and F-tests, as well as tests for multicollinearity and heteroscedasticity, to ensure proper treatment of the data and validity of our estimation model.

We have concluded that generally households do not lower their private savings because of expectation of pension income neither in our data for the G7 nor for the group of 27 OECD countries. 
Based on our findings, we refute the Feldstein's proposition, albeit a new model based on the Gross Replacement Rates (GRR) and a new data set and a new timeframe.

Although, our model and empirical evidence produce plausible results, we are aware of the limited time horizon we have investigated due to limited data points for the GRR. The extension of this study would include a larger data set when more GRR become available, although, we expect no major changes in the outcome of the estimations.

Our research has important policy implication as many countries grapple with revising their social security program, especially those with rising dependency ratio, due to rising longevity and falling birth rates.

\section{ACKNOWLEDGEMENT}

I am indebted to Simon Li (New Paltz, Economics UG ,2017, and a Ph.D. student at Ohio State, Columbus) for his capable research assistance.

\section{REFERENCES}

Attanasio, O. P., \& Brugiavini, A. (2003). "Social Security and Households' Saving.” The Quarterly Journal of Economics, 118(3), 1075-1119.

Retrieved from JSTORwww.jstor.org/stable/25053931.

Barro, R. (1978). "The Impact of Social Security on Private Savings---Evidence from the U.S. Time Series.” Washington, D.C. American Enterprise Institute.

Esposito, L. (1978). "Social Security and Private Saving: Another Look." Social Security Bulletin, May 1979/, 42(5), 33-40.

Feldstein, M. (1974, September-October). "Social Security, Induced Retirement, and Aggregate Capital Accumulation." The Journal of Political Economy, 82 (5), 905-926.

Feldstein, M. S. (1982). Social Security and Private Saving: Reply. Journal of Political Economy, 90(3), 630-642.

Feldstein, M., \& Pellechio, A. (1979). "Social Security and Household Wealth Accumulation: New Microeconometric Evidence." The Review of Economics and Statistics, 61(3), 361-368. Retrieved from JSTOR, www.jstor.org/stable/1926065.

Feldstein, M. (1979, May). "The Effect of Social Security on Private Savings: The Time Series Evidence.” Social Security Bulletin, 42 (5), 36-39.

Gale, W, G. (1998). "The Effects of Pensions on Household Wealth: A Reevaluation of Theory and Evidence." The Journal of Political Economy, 106 (4), 706-723.

Leimer, D. R., \& Lesnoy, S. D. (1982). "Social Security and Private Saving: New Time-Series Evidence." Journal of Political Economy, 90 (3), 606-629.

Retrieved from JSTOR, www.jstor.org/stable/1831373. Retrieved 9/20/17.

Lesnoy, S., \& Leimer, D R. (1985, January). "Social Security and Private Saving: Theory and Historical Evidence." Social Security Bulletin, 48(1), 14-30.

Rocher, S., \& Stierle, M. H. (2015). Household saving rates in the EU: Why do they differ so much? DISCUSSION PAPER 005 | SEPTEMBER 2015.

Slavov, S., Gorry, D., Gorry, A., \& Caliendo, F. N. (2019, March). "Social Security and Saving: An Update." Public Finance Review, 47(2), 312-48

OECD. (2015). Pensions at a Glance 2015: OECD and G20 indicators. OECD Publishing, Paris. Social Security and Private Saving: Another Look. Social Security Bulletin, May 1979, 42(5), 33-40.

OECD. (2016). Household savings (indicator). doi:10.1787/cfc6f499-en. Retrieved February 16, 2016.

OECD. (2016). Long-term interest rates (indicator). doi:10.1787/662d712c-en. Retrieved February 16, 2016, from

http://heinonline.org/HOL/LandingPage?handle=hein.journals/ssbul42\&div=48\&id=\&page Retrieved 9/21/17. 


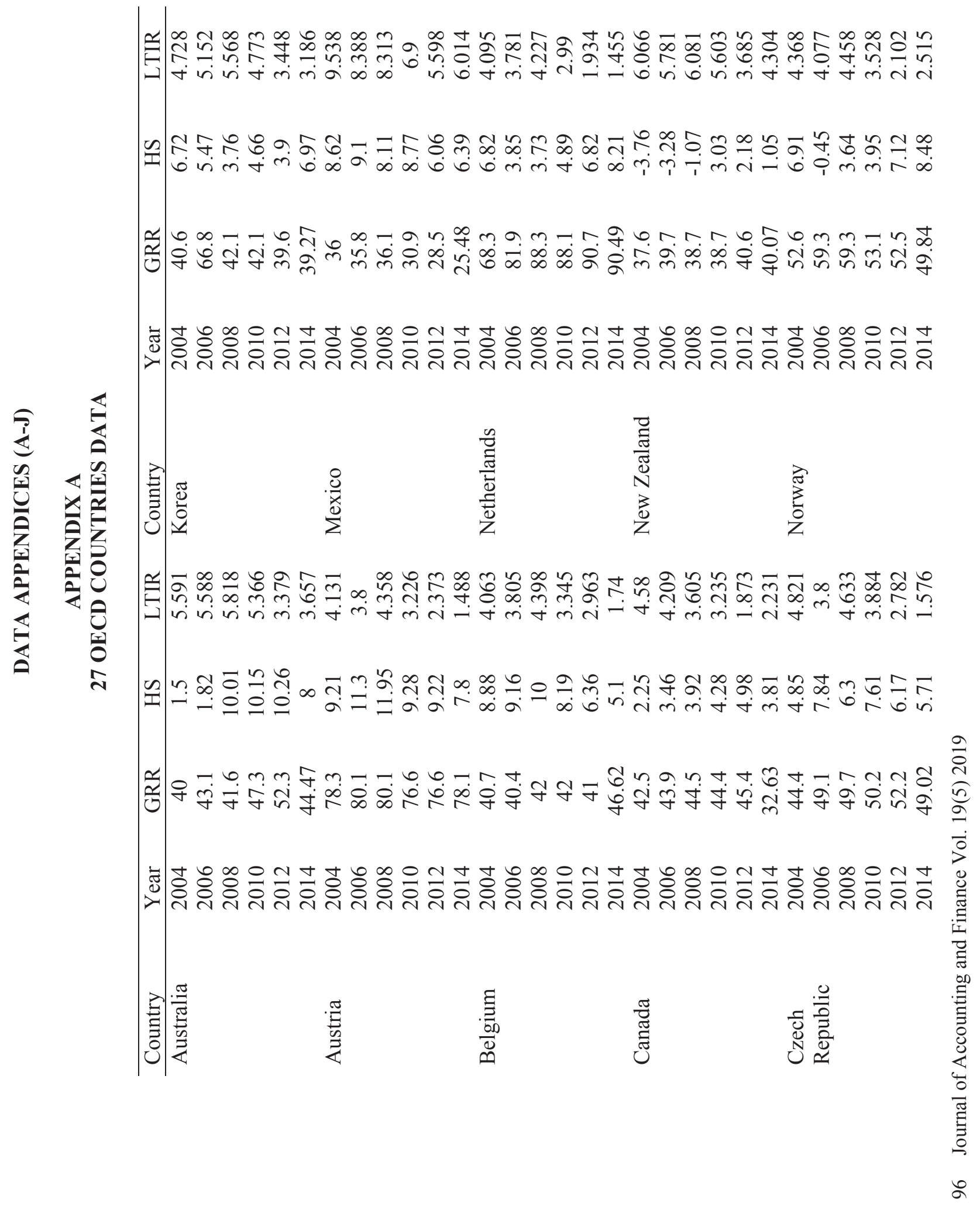


츰

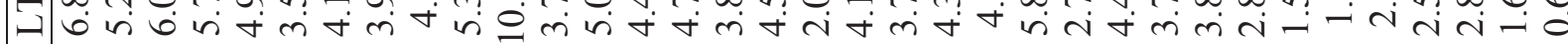

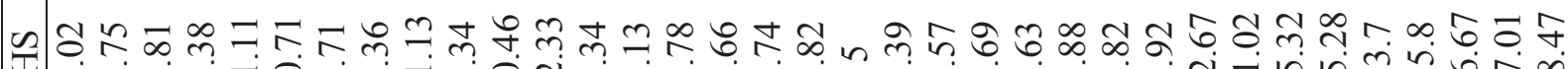

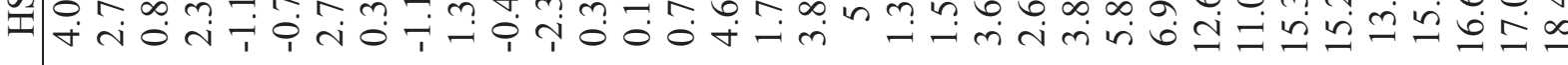

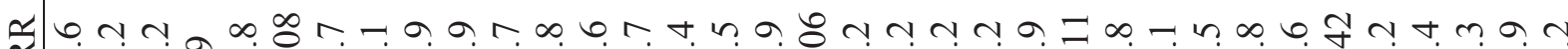

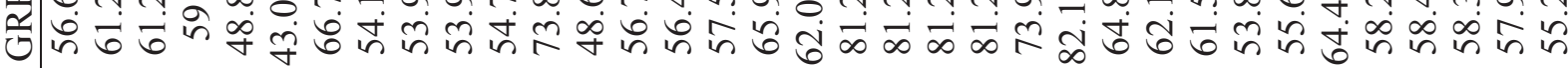

む্خ

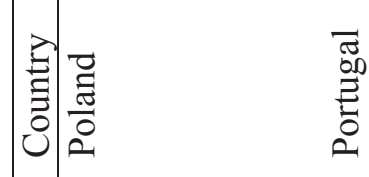

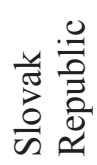

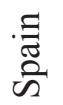

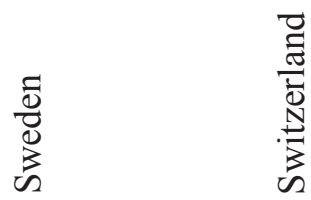

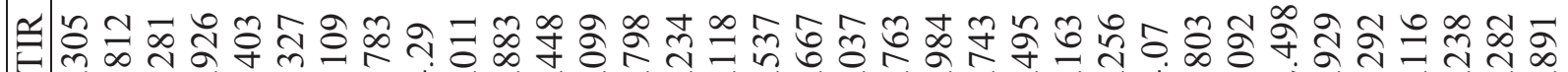
ज将

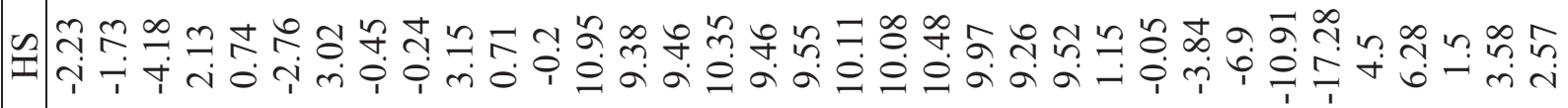

m $m$ m

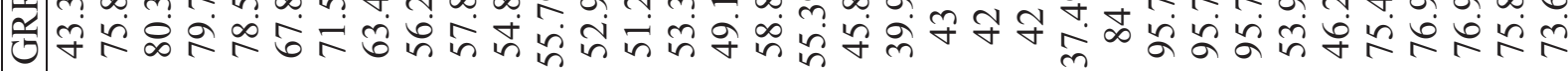

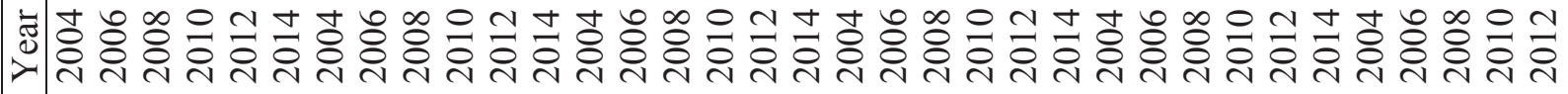
空
点

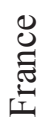
壱
巡
胥 


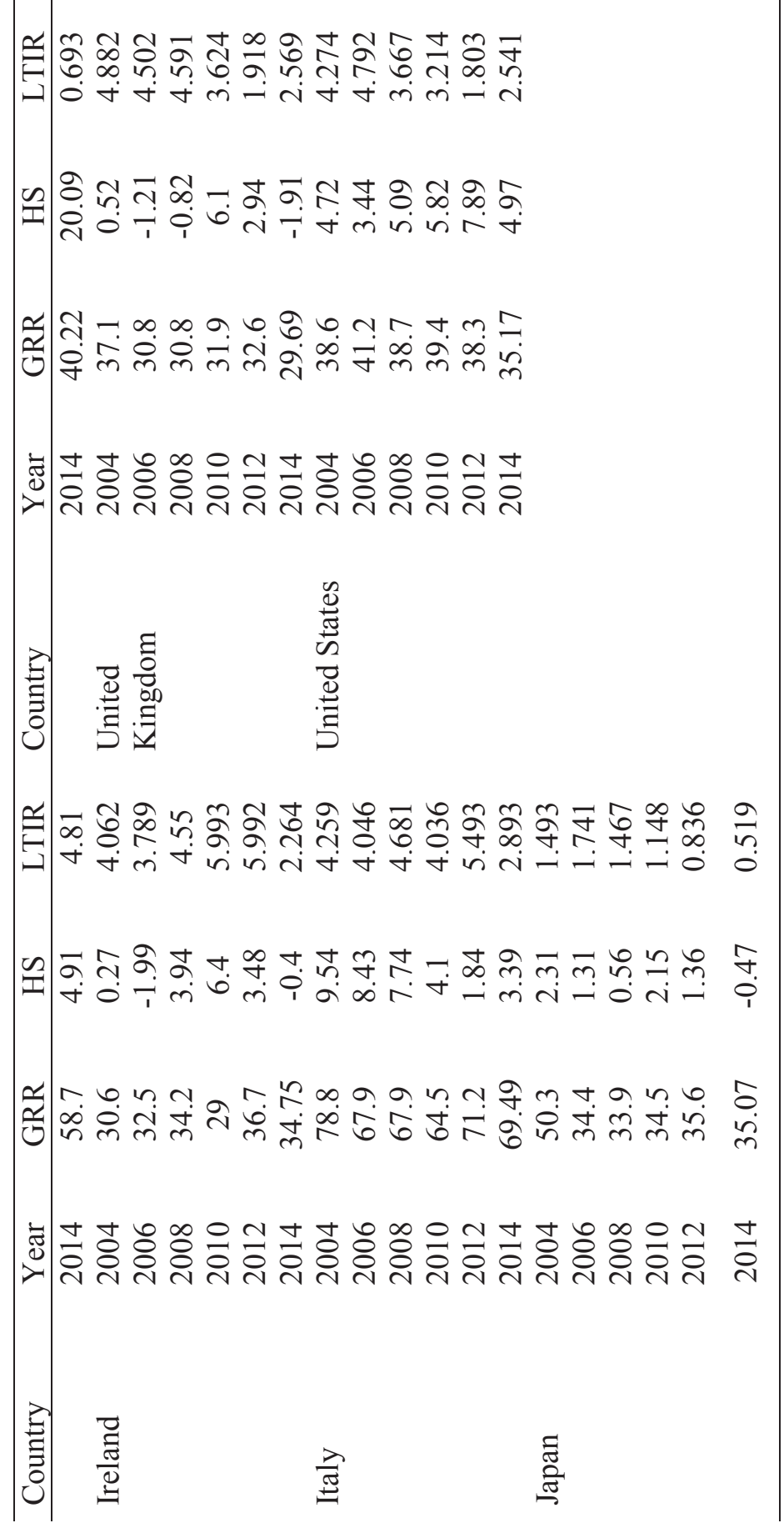


APPENDIX B

AUGMENTED DICKEY-FULLER (ADF) TEST

\begin{tabular}{ccc}
\hline Variable & $D F_{\tau}$ & p-value \\
\hline HS & -5.09 & $<0.01$ \\
GRR & -4.79 & $<0.01$ \\
LTIR & -7.17 & $<0.01$ \\
\hline
\end{tabular}

APPENDIX C

THREE MODEL'S REGRESSION RESULTS FOR 27 OECD COUNTRIES

\begin{tabular}{|c|c|c|c|}
\hline Variable & $\begin{array}{l}\text { Pooled OLS } \\
\text { Coefficient }\end{array}$ & $\begin{array}{l}\text { Fixed Effect } \\
\text { Coefficient }\end{array}$ & $\begin{array}{c}\text { Random Effect } \\
\text { Coefficient }\end{array}$ \\
\hline Intercept & $\begin{array}{l}8.29^{*} \\
(1.44)\end{array}$ & $\begin{array}{l}4.38^{*} \\
(1.82)\end{array}$ & $\begin{array}{c}2.76 \\
(1.78)\end{array}$ \\
\hline GRR & $\begin{array}{l}-0.01 \\
(0.02)\end{array}$ & $\begin{array}{l}0.09 * \\
(0.03)\end{array}$ & $\begin{array}{c}0.06^{*} \\
(0.03)\end{array}$ \\
\hline LTIR & $\begin{array}{c}-0.80 * \\
(0.17)\end{array}$ & $\begin{array}{l}-0.29 * \\
(0.11)\end{array}$ & $\begin{array}{c}-0.37 * \\
(0.11)\end{array}$ \\
\hline$R^{2}$ & 0.13 & 0.84 & 0.11 \\
\hline
\end{tabular}

$*$ indicates significance of the coefficient at 0.05 level.

APPENDIX D

AIC TEST

\begin{tabular}{ll}
\hline Pooled OLS & 973.57 \\
Fixed Effect & 770.08 \\
\hline
\end{tabular}

APPENDIX E

HAUSMAN TEST

\begin{tabular}{cc}
\hline$\chi^{2}$ & 10.74 \\
P-value & $<0.01$ \\
\hline
\end{tabular}

APPENDIX F

F-TEST FOR TIME EFFECT

$\begin{array}{cc}\text { F-stat } & 2.14 \\ \text { P-value } & 0.06\end{array}$

\begin{tabular}{|c|c|}
\hline \multicolumn{2}{|c|}{$\begin{array}{c}\text { APPENDIX G } \\
\text { VARIANCE, INFLATION FACTOR }\end{array}$} \\
\hline Variable & VIF \\
\hline GRR & 7.81 \\
\hline LTIR & 2.71 \\
\hline
\end{tabular}




\section{APPENDIX H \\ BRUESCH-PAGAN (BP)}

\begin{tabular}{ll}
\hline BP stat & 97.22 \\
P-value & $<0.01$ \\
\hline
\end{tabular}

APPENDIX I

HETEROSCEDASTICITY CONSISTENT COEFFICIENTS

\begin{tabular}{cccc}
\hline Variable & Coefficient & Standard Error & P-value \\
\hline GRR & 0.09 & 0.05 & 0.07 \\
LTIR & -0.30 & 0.01 & $<0.0$ \\
& & & \\
\hline
\end{tabular}

APPENDIX J

G7 REGRESSION RESULTS

\begin{tabular}{lcc}
\hline Variable & Fixed-Effect & Heteroskedastic- \\
Regression & Coefficient & Coefficient \\
Intercept & 0.33 & 0.33 \\
GRR & 0.11 & $0.11^{*}$ \\
LTIR & -0.41 & -0.41 \\
$\mathrm{R}^{2}$ & & \\
\hline *indicates significant level at 0.05 & 0.82 &
\end{tabular}

